\title{
Flurbiprofen Loaded Gel Based Topical Delivery System: Formulation and In Vitro Characterization with New Developed UPLC Method
}

\author{
A. Alper Öztürk" Umay Merve Güven², Evrim Yenilmez \\ 1 Anadolu University, Faculty of Pharmacy, Department of Pharmaceutical Technology, Eskişehir, Turkey. \\ 2 Çukurova University, Faculty of Pharmacy, Department of Pharmaceutical Technology, Adana, Turkey
}

\begin{abstract}
Objective: The purpose of this study was to formulate flurbiprofen (FLB) loaded methylcellulose (MC), hydroxypropyl methylcellulose (HPMC) and Carbopol®940 (C-940) based gel formulations with the help of dispersion method for topical application. Additionally, in this study also a new ultra performance liquid chromatography method was developed for the determination of FLB, which was not previously entered into the literature.
\end{abstract}

Method: FLB loaded gel formulations with the help of dispersion method for topical application and to characterize the formulations according to physical appearance, $\mathrm{pH}$, rheology, drug content, dissolution study and release kinetic study with the DDSolver software program. The UPLC method developed was validated for linearity, specificity, precision, sensitivity, accuracy, range and robustness.

Results: Linearity was determined to be at a concentration range of 5-50 $\mu$ g. $\mathrm{mL}^{-1}$. The method developed for FLB was decided to be precise due to RSD values of $<2 \%$. Recovery of the method was satisfactory owing to $<2 \%$ RSD value. The drug content was found to be in the range of $98.14-99.02 \%$ indicating the uniformity of the high drug content. At the 6th hour in dissolution study, the FLB release from gels prepared with MC, HPMC, C-940 reached 99.7\%,99.5\% and 87.60\%, respectively. In the release kinetic tests with DDSolver, the release of gels prepared with MC and HPMC showed conformity with the weibull model, whereas the gel formulation prepared with $\mathrm{C}-940$ showed a zero-order kinetics.

Conclusion: According to the results, all gel formulations prepared have longer release times than the release of pure FLB.

Keywords: Flurbiprofen, UPLC, Topical Gel, DDSolver, Release Kinetics

*Corresponding Author: A. Alper Öztürk, e-mail: aaozturk@anadolu.edu.tr (Received 10 July 2018, accepted 03 August 2018) 


\section{INTRODUCTION}

Nonsteroidal anti-inflammatory drugs (NSAIDs) are among the most popular drugs in the world because of their efficacy in reducing pain and inflammatory reactions. NSAIDs have been documented worldwide for use in many clinical situations such as osteoarthritis, rheumatoid arthritis, ankylosing spondylitis, gout, dysmenorrhea, toothache and headache. ${ }^{1}$ The main pharmacological effect of these group of drugs is the inhibition of the pro-inflammatory enzyme cyclooxygenase (COX). NSAIDs are divided into two groups. The first group is traditional non-selective NSAIDs that specifically inhibit both COX-1 and COX-2. The other group is selective COX-2 inhibitors. ${ }^{2}$ Flurbiprofen (FLB) belongs to the first group of NSAIDs with a molecular weight of $244.3 \mathrm{~g} / \mathrm{mol}$. FLB is commercially available as racemate blend of (+) $\mathrm{S}$ and (-) R-enantiomers. FLB is poorly water soluble but soluble in DMS and ethanol. ${ }^{3}$ Different high performance liquid chromatography (HPLC) methods have been introduced into the literature for the determination of FLB quantities in various biological fluids and pharmaceutical dosage forms. ${ }^{4,5,6,7,8}$ However, the ultra performance liquid chromatography (UPLC) method is not yet available in the literature for FLB. UPLC is accepted as new liquid chromatography. UPLC is defined as "speed, resolution and sensitivity" by 'Waters' that the first manufacturer of the UPLC system. ${ }^{9}$

Gel formulations are very important for the pharmaceutical field and provide better application and stability when compared to creams and ointments. ${ }^{10}$ Topical gel medication is a localized drug delivery system anywhere on the body, via ophthalmic, rectal, vaginal and topical routes via the skin. The skin is one of the most common and easily accessible organs in the human body for topical application and is the main route of topical drug applications. ${ }^{10,11}$ Because of its non-toxic properties, cellulose derivatives are used as emulsifiers, colloidal stabilizers and gel agents in pharmaceutical and food industries. ${ }^{11}$ The methylcellulose (MC) and hydroxypropyl methylcellulose (HPMC) are used for model development and are thermosensitive physical hydrogels. MC is a water-soluble polymer commonly used as a thickener or binder in pharmaceutical, ceramic processing and food applications. HPMC like MC, is used as a hydrophilic carrier material in a wide variety of food and drug applications, especially in oral controlled drug delivery systems. ${ }^{12}$ Carbopol ${ }^{\circledR} 940$ (C-940), a synthetic polymer, has recently been used frequently as part of drug delivery systems. Since the rheological properties are usually investigated by the continuous shear technique which can deform the gel structure, the obtained data does not represent intact gel structure. ${ }^{13} \mathrm{C}-940$ is a hydrophilic polyacrylic acid polymer and the carboxyl groups are highly ionized after neutralization, forming a gel due to the electrostatic compression between the charged polymer chains. The most important point in gels prepared with 
C-940 is that it prevents the skin from escaping from the environment, causing the hydration of the stratum corneum. This leads to intracellular and intercellular channels and "opening" of the pathway for easier passage of drug molecules. ${ }^{14}$

In this study, a new UPLC method for FLB, which was not previously entered into the literature, has been developed and validated. FLB loaded MC, HPMC, C-940 based gels were prepared and characterized for physical appearence, $\mathrm{pH}$, rheology, drug content, dissolution study and release kinetics study with DDSolver software program. The UPLC method developed in this study was used for drug amount and dissolution study.

\section{METHODOLOGY}

\section{Materials}

FLB was obtained from Sanovel (İstanbul/Turkey) as a gift sample. All the other chemicals and reagents used were of analytical grade.

\section{Method development of FLB by UPLC}

26 methods (Method 1 to 26) with varying parameters were tested for best resolution, peak shape and minimum \& accetable retention time at every single day for the condition of the device. Table 1 gives the UPLC parameters for each method and Table 2 shows the UPLC methodology applied for selected method.

Table 1. UPLC method development studies

\begin{tabular}{|c|c|c|c|c|c|}
\hline Method & Mobile phase composition & Ratio & Flow rate & $\underset{(\mathrm{min})}{\mathrm{Rt}}$ & $\begin{array}{c}\text { Peak } \\
\text { morphology }\end{array}$ \\
\hline Method 1 & Acetonitrile: Methanol & $70: 30$ & $0.5 \mathrm{~mL} \cdot \mathrm{dk}^{-1}$ & 0.5 & Sharp peak \\
\hline Method 2 & Acetonitrile: Methanol & $50: 50$ & $0.5 \mathrm{~mL} . \mathrm{dk}^{-1}$ & 0.6 & Sharp peak \\
\hline Method 3 & $\begin{array}{c}\text { Acetonitrile: Methanol: } \\
\text { Water }\end{array}$ & $10: 70: 30$ & $0.5 \mathrm{~mL} \cdot \mathrm{dk}^{-1}$ & 0.5 & Spread peak \\
\hline Method 4 & $\begin{array}{l}\text { Methanol: Water: } \\
\text { Acetic acid \%5 }\end{array}$ & $65: 35: 2$ & $0.5 \mathrm{~mL} \cdot \mathrm{dk}^{-1}$ & 1.2 & Tailed peak \\
\hline Method 5 & Acetonitrile: Methanol & $30: 70$ & $0.5 \mathrm{~mL} . \mathrm{dk}^{-1}$ & 0.1 & Spread peak \\
\hline Method 6 & Acetonitrile: Buffer 1 & $50: 50$ & $0.5 \mathrm{~mL} . \mathrm{dk}^{-1}$ & 0.4 & Sharp peak \\
\hline Method 7 & Methanol: Buffer 1 & $50: 50$ & $0.5 \mathrm{~mL} . \mathrm{dk}^{-1}$ & 0.5 & Tailed peak \\
\hline Method 8 & Acetonitrile: Buffer 1 & $30: 70$ & $0.5 \mathrm{~mL} \cdot \mathrm{dk}^{-1}$ & 0.5 & Spread peak \\
\hline Method 9 & $\begin{array}{c}\text { Acetonitrile: Methanol: } \\
\text { Buffer } 1\end{array}$ & $15: 15: 70$ & $0.5 \mathrm{~mL} \cdot \mathrm{dk}^{-1}$ & 3.0 & Spread peak \\
\hline Method 10 & $\begin{array}{c}\text { Acetonitrile: Methanol: } \\
\text { Buffer } 1\end{array}$ & $15: 15: 70$ & $0.3 \mathrm{~mL} \cdot \mathrm{dk}^{-1}$ & 5.0 & Tailed peak \\
\hline Method 11 & $\begin{array}{c}\text { Acetonitrile: Methanol: } \\
\text { Buffer } 1\end{array}$ & $30: 10: 60$ & $0.5 \mathrm{~mL} \cdot \mathrm{dk}^{-1}$ & 0.7 & Sharp peak \\
\hline
\end{tabular}




\begin{tabular}{|l|c|c|c|c|c|}
\hline Method 12 & $\begin{array}{c}\text { Acetonitrile: Methanol: } \\
\text { Buffer 1 }\end{array}$ & $20: 10: 70$ & $0.5 \mathrm{~mL} \cdot \mathrm{dk}^{-1}$ & 1.7 & Tailed peak \\
\hline Method 13 & Acetonitrile: Buffer 1 & $20: 80)$ & $0.5 \mathrm{~mL} \cdot \mathrm{dk}^{-1}$ & 3.0 & Spread peak \\
\hline Method 14 & $\begin{array}{c}\text { Acetonitrile: Methanol: } \\
\text { Buffer 1 }\end{array}$ & $20: 20: 60$ & $0.5 \mathrm{~mL} \cdot \mathrm{dk}^{-1}$ & 1.0 & Spread peak \\
\hline Method 15 & $\begin{array}{c}\text { Acetonitrile: Methanol: } \\
\text { Buffer 1 }\end{array}$ & $15: 20: 65$ & $0.5 \mathrm{~mL} \cdot \mathrm{dk}^{-1}$ & 2.0 & Tailed peak \\
\hline Method 16 & $\begin{array}{c}\text { Acetonitrile: Methanol: } \\
\text { Buffer 1 }\end{array}$ & $15: 30: 55$ & $0.5 \mathrm{~mL} \cdot \mathrm{dk}^{-1}$ & 1.0 & Sharp peak \\
\hline Method 17 & $\begin{array}{c}\text { Acetonitrile: Methanol: } \\
\text { Buffer 1 }\end{array}$ & $15: 25: 60$ & $0.5 \mathrm{~mL} \cdot \mathrm{dk}^{-1}$ & 1.5 & Sharp peak \\
\hline Method 18 & $\begin{array}{c}\text { Acetonitrile: Methanol: } \\
\text { Buffer 1 }\end{array}$ & $15: 15: 70$ & $0.6 \mathrm{~mL} \cdot \mathrm{dk}^{-1}$ & 2.0 & Spread peak \\
\hline Method 19 & $\begin{array}{c}\text { Acetonitrile: Methanol: } \\
\text { Buffer 1 }\end{array}$ & $25: 15: 60$ & $0.4 \mathrm{~mL} \cdot \mathrm{dk}^{-1}$ & 1.0 & Tailed peak \\
\hline Method 20 & $\begin{array}{c}\text { Acetonitrile: Methanol: } \\
\text { Buffer 2 }\end{array}$ & $20: 20: 60$ & $0.5 \mathrm{~mL} \cdot \mathrm{dk}^{-1}$ & 3.0 & Tailed peak \\
\hline Method 21 & $\begin{array}{c}\text { Acetonitrile: Methanol: } \\
\text { Buffer 2 }\end{array}$ & $30: 20: 50$ & $0.5 \mathrm{~mL} \cdot \mathrm{dk}^{-1}$ & 0.7 & Tailed peak \\
\hline Method 22 & $\begin{array}{c}\text { Acetonitrile: Methanol: } \\
\text { Buffer 2 }\end{array}$ & $20: 30: 50$ & $0.5 \mathrm{~mL} \cdot \mathrm{dk}^{-1}$ & 0.4 & Tailed peak \\
\hline Method 23 & $\begin{array}{c}\text { Acetonitrile: Methanol: } \\
\text { Buffer 2 }\end{array}$ & $30: 10: 60$ & $0.3 \mathrm{~mL} \cdot \mathrm{dk}^{-1}$ & 1.0 & Sharp peak \\
\hline Method 24 & $\begin{array}{c}\text { Acetonitrile: Methanol: } \\
\text { Buffer 1 }\end{array}$ & $30: 20: 50$ & $0.3 \mathrm{~mL} \cdot \mathrm{dk}^{-1}$ & 1.7 & Sharp peak \\
\hline Method 25 & $\begin{array}{c}\text { Acetonitrile: Methanol: } \\
\text { Buffer 1 }\end{array}$ & $30: 20: 50$ & $0.1{\mathrm{~mL} \cdot \mathrm{dk}^{-1}}^{\text {Buffer 1 }}$ & 0.8 & Spread peak \\
\hline $\begin{array}{c}\text { Acetonitrile: Methanol: } \\
\text { Method 26 }\end{array}$ & $30: 30: 40$ & $0.2{\mathrm{~mL} \cdot \mathrm{dk}^{-1}}$ & 2.0 & Sharp peak \\
\hline
\end{tabular}

${ }^{*}$ Rt: Retention time (minute), ${ }^{*}$ Buffer 1: $30 \mathrm{mM}$ disodium hydrogen phosphate buffer,

*Buffer 2: 0.05 M Potassium dihydrogen phosphate buffer

Table 2. Summary conditions of the UPLC method

\begin{tabular}{|c|c|}
\hline Device & Agilent Technology 1290 Infinity \\
\hline Column & \begin{tabular}{c} 
Zorbax Eclipse Plus C18 $(2.1 \times 50 \mathrm{~mm}, 1.8 \mu \mathrm{m})$ \\
\hline Mobile phase
\end{tabular} \\
$\begin{array}{c}30: 30: 40(\mathrm{v} / \mathrm{v} / \mathrm{v}) \text { acetonitrile:methanol: } 30 \mathrm{mM} \\
\text { disodium hydrogen phosphate buffer }\end{array}$ \\
\hline Oven temperature & $40^{\circ} \mathrm{C}$ \\
\hline Flow rate & $0.2 \mathrm{~mL} \cdot \mathrm{min}^{-1}$ \\
\hline İnjection volume & $0.5 \mu \mathrm{L}$ \\
\hline Wavelength & 247 \\
\hline
\end{tabular}


UPLC device (Agilent Technology 1290 Infinity) used was mounted with reversed-phase (RP) Zorbax $\AA$ Eclipse Plus $\mathrm{C} 18$ gravity column (column length: $50 \mathrm{~mm}$, column diameter: $2.1 \mathrm{~mm}$, particle diameter: $1.8 \mu \mathrm{m}) .30: 30: 40(\mathrm{v} / \mathrm{v} / \mathrm{v})$ acetonitrile: methanol: $30 \mathrm{mM}$ disodium hydrogen phosphate buffer was used as the mobile phase for perfect resolution of FLB. Flow rate of the mobile phase was set to $0.2 \mathrm{~mL} \cdot \mathrm{min}^{-1}$ and $0.5 \mu \mathrm{L}$ invariable volume of specimen were injected by an automatic injector. Temperature of the column was set to $40^{\circ} \mathrm{C}$ while a fluorescent detector was used at $247 \mathrm{~nm}$.

\section{Method validation of FLB by UPLC}

\section{Linearity and Range}

Linearity is a common study used to check the linearity of a calibration curve by examining the correlation coefficient. ${ }^{15}$ Aliquots from a standard stock solution (250 $\mu \mathrm{g} \bullet \mathrm{mL}^{-1}$ ) of FLB were used to prepare different sets of dilutions. A series of dilutions consisted of 10 different concentrations of FLB in the range of $5-50 \mu \mathrm{g}^{-\mathrm{mL}^{-1}}$. Absorbance values were measured and calculations were made to determine FLB concentration. The specified range is derived from linearity studies and depends on the intended application of the procedure.16 Therefore, a standard stock solution $\left(250 \mu \mathrm{g} \cdot \mathrm{mL}^{-1}\right)$ of FLB were used to prepare in the range of 5-250 $\mu \mathrm{g} \cdot \mathrm{mL}^{-1}$.

\section{Specificity}

The specificity of the UPLC method was determined by complete separation of the FLB with the mobile phase, $\mathrm{pH} 7.4$ buffer and then the effect of the excipients used in the gel formulation was investigated with placebo formulations to determine whether or not they have been interfered.

\section{Precision}

Precision is an extremely important criterion for all analysis that exhibits "closeness to agreement" between a set of measurements. ${ }^{17}$ Intermediate precision and repeatability values when using the device in this study was verified by repeated scanning and measurement of absorbances $(\mathrm{n}=6)$ for FLB $\left(15 \mu \mathrm{g} \bullet \mathrm{mL}^{-1}, 30 \mu \mathrm{g} \bullet \mathrm{mL}^{-1}\right.$, $\left.45 \mu \mathrm{g} \bullet \mathrm{mL}^{-1}\right)$. Repeatability studies were performed six times on the same day by analyzing three different concentrations of $15 \mu \mathrm{g} \bullet \mathrm{mL}^{-1}, 30 \mu \mathrm{g} \bullet \mathrm{mL}^{-1}, 45 \mu \mathrm{g} \cdot \mathrm{mL}^{-1}$ for FLB. Repeating tests on three consecutive days verified intermediate precision of the method. Results were expressed as RSD\% of the measurements obtained.

\section{Limit of detection and limit of quantitation (sensitivity)}

Detection and quantification limits are the two principal components of method validation [18]. Limit of Detection (LOD) and Limit of Quantitation (LOQ) were 
separately determined based on the calibration curve obtained according to ICH Q2 (R1) recommendations (Eq. 1, Eq. 2). Standard deviation of y-intercept and slope of the calibration curve were used to calculate LOD and LOQ, respectively.

$\mathrm{LOD}=3.3 \times \sigma / \mathrm{S} \quad$ Equation 1

$\mathrm{LOQ}=10 \times \sigma / \mathrm{S} \quad$ Equation 2

where, $\sigma=$ the standard deviation of the response and $S=$ slope of the calibration curve.

\section{Accuracy}

Accuracy was calculated as deviation of mean from nominal concentration. ${ }^{19}$ Accuracy of the method used was determined by calculating recoveries of FLB by standard addition method. Standard solutions containing specific amount of FLB $\left(20 \mu \mathrm{g} \bullet \mathrm{mL}^{-1}, 30 \mu \mathrm{g} \bullet \mathrm{mL}^{-1}, 40 \mu \mathrm{g} \bullet \mathrm{mL}^{-1}\right)$ were used and percentage of recoveries were calculated.

\section{Robustness}

Robustness is the measure of the analytical method's ability to remain unaffected by small changes in method parameters. The factors chosen for this Robustness study were the wavelength $(\mathrm{nm})$, temperature $\left({ }^{\circ} \mathrm{C}\right)$, flow (mL.min-1), $\mathrm{pH}$ of mobile phase. The factors are shown in Table 3.

Table 3. Experimental design of the robustness study

\begin{tabular}{|c|c|c|c|c|}
\hline No & $\begin{array}{c}\text { Wavelength } \\
(\mathbf{n m})\end{array}$ & $\begin{array}{c}\text { Temperature } \\
\left({ }^{\circ} \mathbf{C}\right)\end{array}$ & $\begin{array}{c}\text { Flow rate }(\mathbf{m l} . \\
\mathbf{m i n}^{-1} \mathbf{)}\end{array}$ & $\begin{array}{c}\mathbf{p H} \text { of mobile } \\
\text { phase }\end{array}$ \\
\hline 1 & 247 & 37 & 0.20 & 7.4 \\
\hline 2 & 247 & 37 & 0.18 & 7.8 \\
\hline 3 & 245 & 40 & 0.18 & 7.8 \\
\hline 4 & 245 & 40 & 0.20 & 7.4 \\
\hline 5 & 247 & 40 & 0.18 & 7.4 \\
\hline 6 & 245 & 37 & 0.20 & 7.8 \\
\hline
\end{tabular}

\section{Preparation of gel formulations}

The composition of FLB topical gel formulations are shown in Table 4 and Table 5 . For water-based formulations, the amount of polymer required was weighed and sprinkled on the water surface at about 500 rpm for 2 hours (Solution A). $0.5 \mathrm{~g}$ FLB is then dissolved in the appropriate amount of alcohol, glycerin (GLY) and propylene glycol (PG) (Solution B). Finally, solution B was added into solution A under magnetic stirring. These two mixtures were further stirred under continuous stirring for 2 hours. 
For dimethyl sulfoxide (DMSO) based formulations, the amount of polymer required was weighed and sprinkled on the DMSO surface at about 500 rpm for 2 hours (Solution C). 0.5 g FLB is then dissolved in the appropriate amount of alcohol, glycerin and propylene glycol (Solution D). Finally, solution D was added into Solution $\mathrm{C}$ under stirring. These two mixtures were further stirred under continuous stirring for 2 hours. The gel formulations prepared were filled into aluminum collapsible tubes for characterization studies, folded and sealed.

Table 4. Gel formulations prepared with distilled water

\begin{tabular}{|c|c|c|c|c|c|c|c|c|}
\hline Code & $\begin{array}{c}\text { MC } \\
\mathbf{( g )}\end{array}$ & $\begin{array}{c}\text { HPMC } \\
\mathbf{( g )}\end{array}$ & $\begin{array}{c}\mathbf{C - 9 4 0} \\
\mathbf{( g )}\end{array}$ & $\begin{array}{c}\mathbf{G L Y} \\
\mathbf{( g )}\end{array}$ & $\begin{array}{c}\text { PG } \\
\mathbf{( g )}\end{array}$ & $\begin{array}{c}\text { D. water } \\
\mathbf{( g )}\end{array}$ & $\begin{array}{c}\text { Alcohol } \\
\mathbf{( g )}\end{array}$ & $\begin{array}{c}\text { FLB } \\
\mathbf{( g )}\end{array}$ \\
\hline A-1 & 0.200 & - & - & 1.000 & 1.000 & 5.300 & 2.000 & - \\
\hline A-2 & 0.250 & - & - & 1.000 & 1.000 & 5.250 & 2.000 & - \\
\hline A-3 & 0.300 & - & - & 1.000 & 1.000 & 5.200 & 2.000 & - \\
\hline A-4 & 0.400 & - & - & 1.000 & 1.000 & 5.100 & 2.000 & - \\
\hline A-5 & 0.500 & - & - & 1.000 & 1.000 & 5.000 & 2.000 & - \\
\hline A-6 & 0.200 & - & - & 1.000 & 1.000 & 5.300 & 2.000 & 0.500 \\
\hline A-7 & 0.250 & - & - & 1.000 & 1.000 & 5.250 & 2.000 & 0.500 \\
\hline A-8 & 0.300 & - & - & 1.000 & 1.000 & 5.200 & 2.000 & 0.500 \\
\hline A-9 & 0.400 & - & - & 1.000 & 1.000 & 5.100 & 2.000 & 0.500 \\
\hline A-10 & 0.500 & - & - & 1.000 & 1.000 & 5.000 & 2.000 & 0.500 \\
\hline B-1 & - & 0.200 & - & 1.000 & 1.000 & 5.300 & 2.000 & - \\
\hline B-2 & - & 0.250 & - & 1.000 & 1.000 & 5.250 & 2.000 & - \\
\hline B-3 & - & 0.300 & - & 1.000 & 1.000 & 5.200 & 2.000 & - \\
\hline B-4 & - & 0.400 & - & 1.000 & 1.000 & 5.100 & 2.000 & - \\
\hline B-5 & - & 0.500 & - & 1.000 & 1.000 & 5.000 & 2.000 & - \\
\hline B-6 & - & 0.200 & - & 1.000 & 1.000 & 5.300 & 2.000 & 0.500 \\
\hline B-7 & - & 0.250 & - & 1.000 & 1.000 & 5.250 & 2.000 & 0.500 \\
\hline B-8 & - & 0.300 & - & 1.000 & 1.000 & 5.200 & 2.000 & 0.500 \\
\hline B-9 & - & 0.400 & - & 1.000 & 1.000 & 5.100 & 2.000 & 0.500 \\
\hline B-10 & - & 0.500 & - & 1.000 & 1.000 & 5.000 & 2.000 & 0.500 \\
\hline C-1 & - & - & 0.040 & 1.000 & 1.000 & 5.960 & 2.000 & - \\
\hline C-2 & - & - & 0.050 & 1.000 & 1.000 & 5.950 & 2.000 & - \\
\hline C-3 & - & - & 0.100 & 1.000 & 1.000 & 5.900 & 2.000 & - \\
\hline C-4 & - & - & 0.150 & 1.000 & 1.000 & 5.850 & 2.000 & - \\
\hline C-5 & - & - & 0.200 & 1.000 & 1.000 & 5.800 & 2.000 & - \\
\hline C-6 & - & - & 0.040 & 1.000 & 1.000 & 5.960 & 2.000 & 0.500 \\
\hline C-7 & - & - & 0.050 & 1.000 & 1.000 & 5.950 & 2.000 & 0.500 \\
\hline C-8 & - & - & 0.100 & 1.000 & 1.000 & 5.900 & 2.000 & 0.500 \\
\hline C-9 & - & - & 0.150 & 1.000 & 1.000 & 5.850 & 2.000 & 0.500 \\
\hline C-10 & - & - & 0.200 & 1.000 & 1.000 & 5.800 & 2.000 & 0.500 \\
\hline & & & & & & & & \\
\hline
\end{tabular}

*g: gram 
Table 5. Gel formulations prepared with DMSO

\begin{tabular}{|c|c|c|c|c|c|c|c|c|}
\hline Code & $\begin{array}{c}\text { MC } \\
\mathbf{( g )}\end{array}$ & $\begin{array}{c}\text { HPMC } \\
\mathbf{( g )}\end{array}$ & $\begin{array}{c}\mathbf{C - 9 4 0} \\
\mathbf{( g )}\end{array}$ & $\begin{array}{c}\text { GLY } \\
\mathbf{( g )}\end{array}$ & $\begin{array}{c}\mathbf{P G} \\
\mathbf{( g )}\end{array}$ & $\begin{array}{c}\text { DMSO } \\
\mathbf{( g )}\end{array}$ & $\begin{array}{c}\text { Alcohol } \\
\mathbf{( g )}\end{array}$ & $\begin{array}{c}\text { FLB } \\
\mathbf{( g )}\end{array}$ \\
\hline D-1 & 0.200 & - & - & 2.000 & 2.000 & 2.300 & 3.000 & - \\
\hline D-2 & 0.250 & - & - & 2.000 & 2.000 & 2.250 & 3.000 & - \\
\hline D-3 & 0.300 & - & - & 2.000 & 2.000 & 2.200 & 3.000 & - \\
\hline D-4 & 0.400 & - & - & 2.000 & 2.000 & 2.100 & 3.000 & - \\
\hline D-5 & 0.500 & - & - & 2.000 & 2.000 & 2.000 & 3.000 & - \\
\hline D-6 & 0.200 & - & - & 2.000 & 2.000 & 2.300 & 3.000 & 0.500 \\
\hline D-7 & 0.250 & - & - & 2.000 & 2.000 & 2.250 & 3.000 & 0.500 \\
\hline D-8 & 0.300 & - & - & 2.000 & 2.000 & 2.200 & 3.000 & 0.500 \\
\hline D-9 & 0.400 & - & - & 2.000 & 2.000 & 2.100 & 3.000 & 0.500 \\
\hline D-10 & 0.500 & - & - & 2.000 & 2.000 & 2.000 & 3.000 & 0.500 \\
\hline E-1 & - & 0.200 & - & 2.000 & 2.000 & 2.300 & 3.000 & - \\
\hline E-2 & - & 0.250 & - & 2.000 & 2.000 & 2.250 & 3.000 & - \\
\hline E-3 & - & 0.300 & - & 2.000 & 2.000 & 2.200 & 3.000 & - \\
\hline E-4 & - & 0.400 & - & 2.000 & 2.000 & 2.100 & 3.000 & - \\
\hline E-5 & - & 0.500 & - & 2.000 & 2.000 & 2.000 & 3.000 & - \\
\hline E-6 & - & 0.200 & - & 2.000 & 2.000 & 2.300 & 3.000 & 0.500 \\
\hline E-7 & - & 0.250 & - & 2.000 & 2.000 & 2.250 & 3.000 & 0.500 \\
\hline E-8 & - & 0.300 & - & 2.000 & 2.000 & 2.200 & 3.000 & 0.500 \\
\hline E-9 & - & 0.400 & - & 2.000 & 2.000 & 2.100 & 3.000 & 0.500 \\
\hline E-10 & - & 0.500 & - & 2.000 & 2.000 & 2.000 & 3.000 & 0.500 \\
\hline F-1 & - & - & 0.040 & 2.000 & 2.000 & 2.960 & 3.000 & - \\
\hline F-2 & - & - & 0.050 & 2.000 & 2.000 & 2.950 & 3.000 & - \\
\hline F-3 & - & - & 0.100 & 2.000 & 2.000 & 2.900 & 3.000 & - \\
\hline F-4 & - & - & 0.150 & 2.000 & 2.000 & 2.850 & 3.000 & - \\
\hline F-5 & - & - & 0.200 & 2.000 & 2.000 & 2.800 & 3.000 & - \\
\hline F-6 & - & - & 0.040 & 2.000 & 2.000 & 2.960 & 3.000 & 0.500 \\
\hline F-7 & - & - & 0.050 & 2.000 & 2.000 & 2.950 & 3.000 & 0.500 \\
\hline F-8 & - & - & 0.100 & 2.000 & 2.000 & 2.900 & 3.000 & 0.500 \\
\hline F-9 & - & - & 0.150 & 2.000 & 2.000 & 2.850 & 3.000 & 0.500 \\
\hline F-10 & - & - & 0.200 & 2.000 & 2.000 & 2.800 & 3.000 & 0.500 \\
\hline
\end{tabular}

*g: gram

\section{Gel characterization studies}

\section{Physical appearence}

The prepared gel formulations were inspected visually for their colour and homogeneity. 


\section{pH}

The $\mathrm{pH}$ of the FLB loaded gels were determined using digital $\mathrm{pH}$ meter (Mettler Toledo $^{\mathrm{TM}}$ S220 SevenCompact ${ }^{\mathrm{TM}} \mathrm{pH} /$ lon Benchtop Meter). The measurements were taken for average of 3 times.

\section{Rheological Characterization}

Rheological properties were determined using a cone-and-plate geometry rheometer with a diameter of $40 \mathrm{~mm}$ (Brookfield, USA). Measurements and viscosity changes were repeated at $25 \pm 1^{\circ} \mathrm{C}$ temperatures. Shear rates against shear stress were calculated. Measurements provide further information about flow properties.

\section{Drug content}

Fully weighed $1 \mathrm{~g}$ of gel was removed and dissolved in $100 \mathrm{~mL}$ of $\mathrm{pH} 7.4$ phosphate buffer. The volumetric flask containing the gel solution was agitated for 2 hours on a mechanical shaker to obtain the complete solubility of the drug. This solution was filtered using a Millipore filter $(0.45 \mu \mathrm{m})$. After appropriate dilution, it was analyzed by the developed UPLC method. Measurements were repeated three times.

\section{Dissolution study}

In vitro release study of the gel formulations was investigated for 6 hours time. In vitro drug release of FLB from gel formulations were studied through dialysis bag (cellulose membrane) which was sealed with clamps and stirred at $250 \mathrm{rpm}$ using magnetic stirrer. The temperature was maintained at $37 \pm 0.5^{\circ} \mathrm{C}$ under sink conditions. Gel formulation equivalent to $0.2 \mathrm{~g}$ of drug and $0.2 \mathrm{~g}$ pure FLB were transferred into dialysis membrane which was previously soaked in dissolution medium for 12 hours, tied properly at both the ends and kept inside the glass. The in vitro release studies were performed in phosphate buffer ( $\mathrm{pH}$ 7.4). ${ }^{20}$ Samples were collected at certain intervals from the release media and the same volume was completed with a fresh dissolution medium. The samples were then analysed by a developed and validated UPLC method.

\section{Release kinetics}

To determine the release kinetics, data obtained from in vitro drug release studies in phosphate buffer ( $\mathrm{pH}$ 7.4) were analyzed by a software program DDSolver. $^{21}$ 


\section{RESULTS AND DISCUSSION}

\section{Method development and validation of FLB by UPLC}

Different proportions of acetonitril:methanol:30mM disodium hydrogen phosphate buffer and acetonitril: methanol:0.05M Potassium dihydrogen phosphate buffer and flow rates were tested for method optimization and it was found that acetonitril: methanol:30 $\mathrm{mM}$ disodium hydrogen phosphate buffer the proportion of 30:30:40 v/v/v and a flow rate of $0.2 \mathrm{~mL} \mathrm{~min}^{-1}$ give admissible retention time (RT) and good resolution for both the mobile phase, placebo formulations, pH 7.4 buffer and FLB.

\section{Linearity and Range}

Linearity range of FLB for the method used was found to be $5-50 \mu \mathrm{g} \cdot \mathrm{mL}^{-1}$ while regression equation was determined to be $\mathrm{y}=152920 \mathrm{x}-206333$ by plotting concentration (x) versus peak area (y). Correlation coefficient $\left(\mathrm{R}^{2}\right)$ of 0.9999 was highly significant. Linearity test results are shown in Table 6 and regression curve is presented in Figure 1.

Table 6. Series and area values prepared for linearity study

\begin{tabular}{|c|c|c|c|c|c|c|}
\hline \multirow{2}{*}{$\begin{array}{c}\text { CONC } \\
\left(\boldsymbol{\mu g} \cdot \mathbf{m L}^{-1}\right)\end{array}$} & \multicolumn{6}{|c|}{ Area/Rt } \\
\cline { 2 - 7 } & SET 1 & SET 2 & SET 3 & Mean & SD & SE \\
\hline 5.0 & 61.7205 & 59.4184 & 58.3159 & 59.8183 & 1.7372 & 0.7092 \\
\hline 10.0 & 132.6282 & 130.8683 & 134.4335 & 132.6433 & 1.7826 & 0.7278 \\
\hline 15.0 & 203.9623 & 206.8451 & 206.6789 & 205.8288 & 1.6185 & 0.6608 \\
\hline 20.0 & 285.7185 & 283.5822 & 281.8051 & 283.7019 & 1.9594 & 0.7999 \\
\hline 25.0 & 363.9279 & 360.1898 & 358.7766 & 360.9648 & 2.6617 & 1.0866 \\
\hline 30.0 & 439.5623 & 440.0372 & 433.7357 & 437.7784 & 3.5092 & 1.4326 \\
\hline 35.0 & 520.3603 & 509.4565 & 510.3425 & 513.3864 & 6.0557 & 2.4722 \\
\hline 40.0 & 590.8665 & 591.0432 & 587.2816 & 589.7304 & 2.1226 & 0.8665 \\
\hline 45.0 & 672.6392 & 666.9029 & 668.4010 & 669.3143 & 2.9752 & 1.2146 \\
\hline 50.0 & 753.8879 & 748.1176 & 735.3897 & 745.7984 & 9.4647 & 3.8639 \\
\hline 75.0 & 1113.503 & 1116.422 & 1158.8123 & 1129.579 & 25.3588 & 10.3527 \\
\hline 90.0 & 1368.832 & 1380.642 & 1371.7079 & 1373.727 & 6.1587 & 2.5143 \\
\hline 120.0 & 1799.558 & 1824.454 & 1853.7453 & 1825.919 & 27.1236 & 11.0731 \\
\hline 150.0 & 2230.738 & 2266.369 & 2309.2433 & 2268.784 & 39.3083 & 16.0476 \\
\hline 200.0 & 3003.514 & 3039.887 & 3063.1810 & 3035.528 & 30.0712 & 12.2765 \\
\hline 250.0 & 3808.190 & 3792.207 & 3856.2010 & 3818.866 & 33.3061 & 13.5972 \\
\hline
\end{tabular}




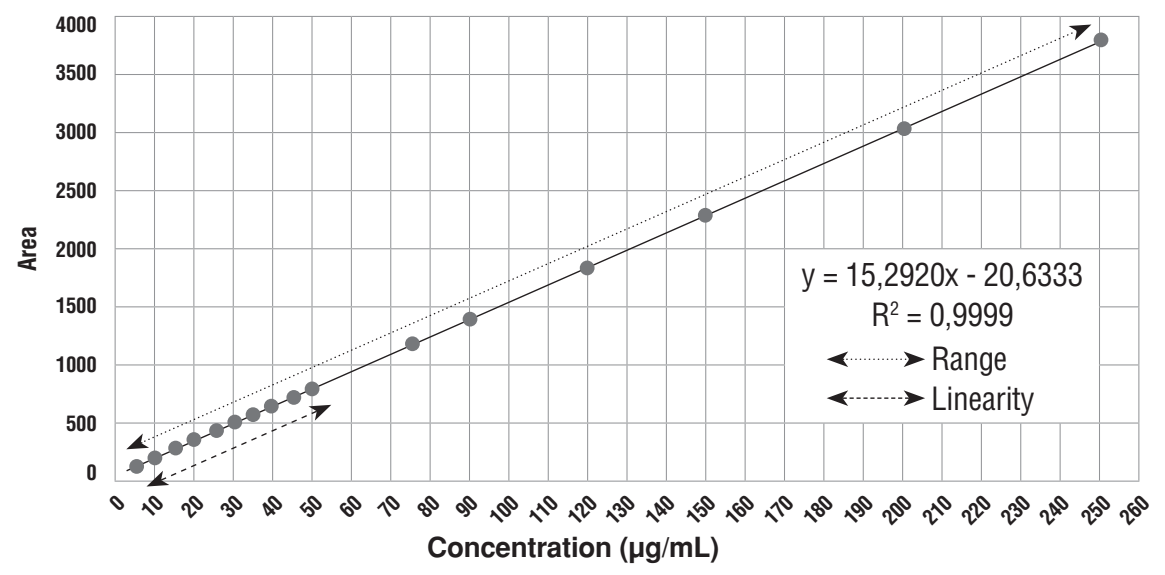

Figure 1. Regression profile of FLB.

Range is the interval between the upper and lower concentration of active agent that have been indicated to be determined with precision, accuracy and linearity using the method as written. ${ }^{22}$ The accuracy and precision of the method are within the acceptable range. In this study the range was observed linearly to the highest concentration (250 $\left.\mu \mathrm{g} . \mathrm{mL}^{-1}, \mathrm{R} 2: 0.9999\right)$.

\section{Specificity and peak morphology}

Characteristic UPLC chromatogram of FLB is given at Figure 2. It can be seen that chromatogram recorded for the combination of non-functioning components exposed no peaks at retention time of 2.0 minutes (Figure 3 and Figure 4).

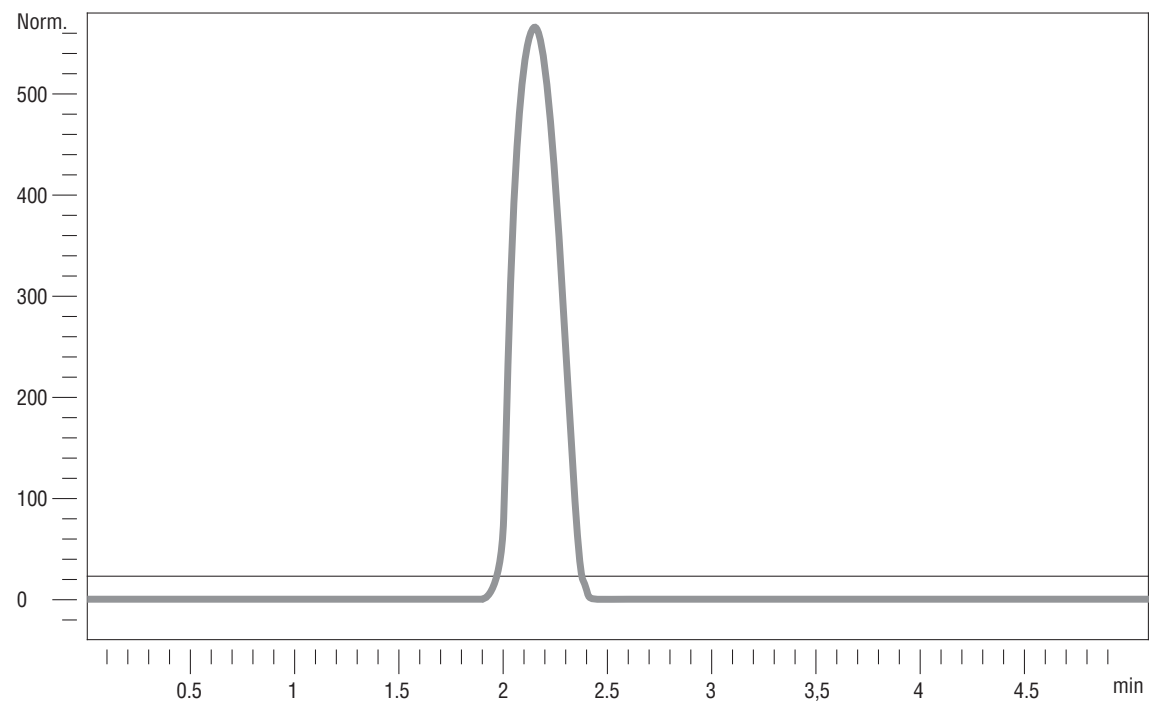

Figure 2. Chromatogram of FLB 

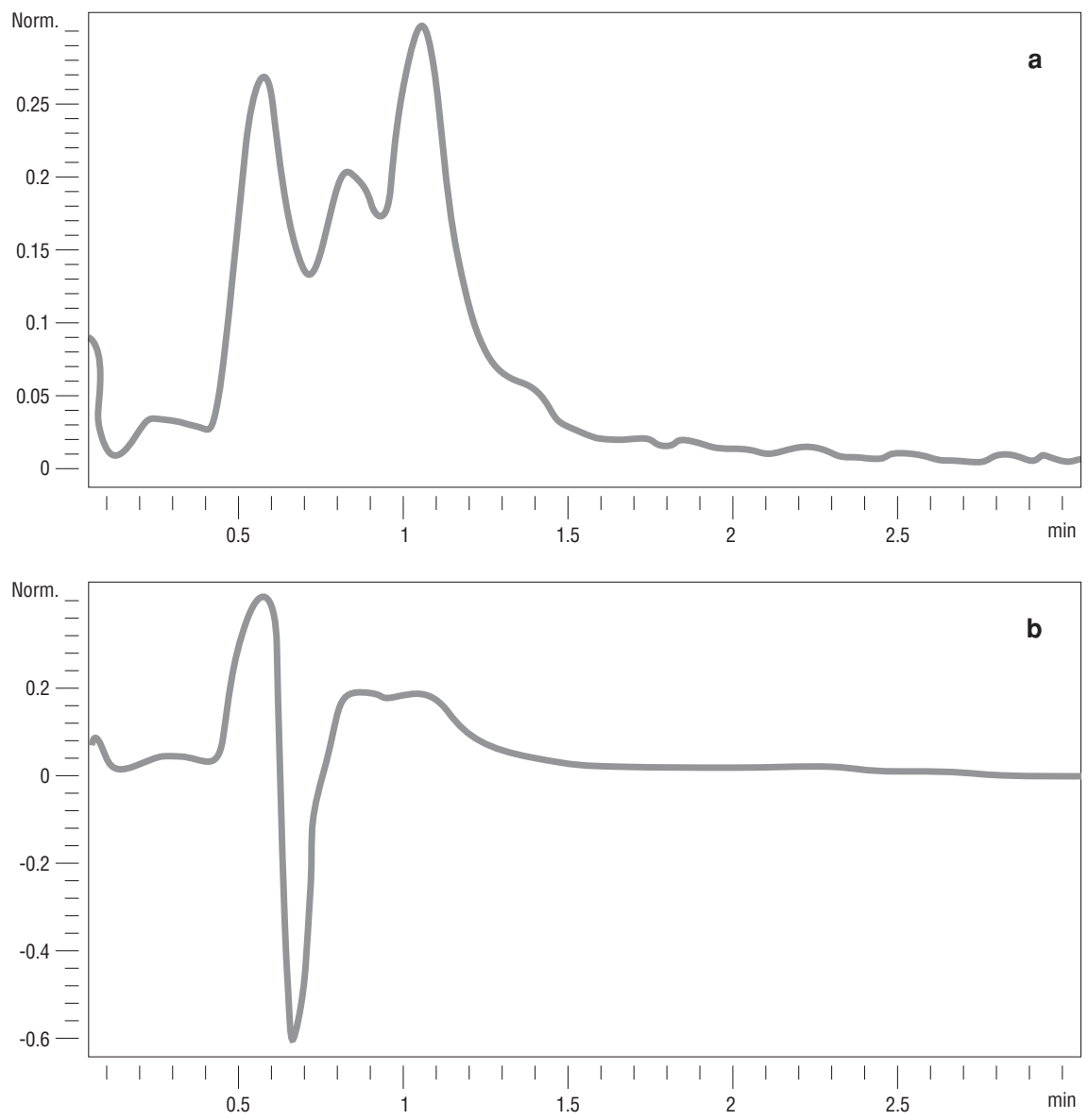

Figure 3. Chromatogram of Mobile phase and pH 7.4 phosphate buffer a: mobile phase b: $\mathrm{pH} 7.4$ phosphate buffer 

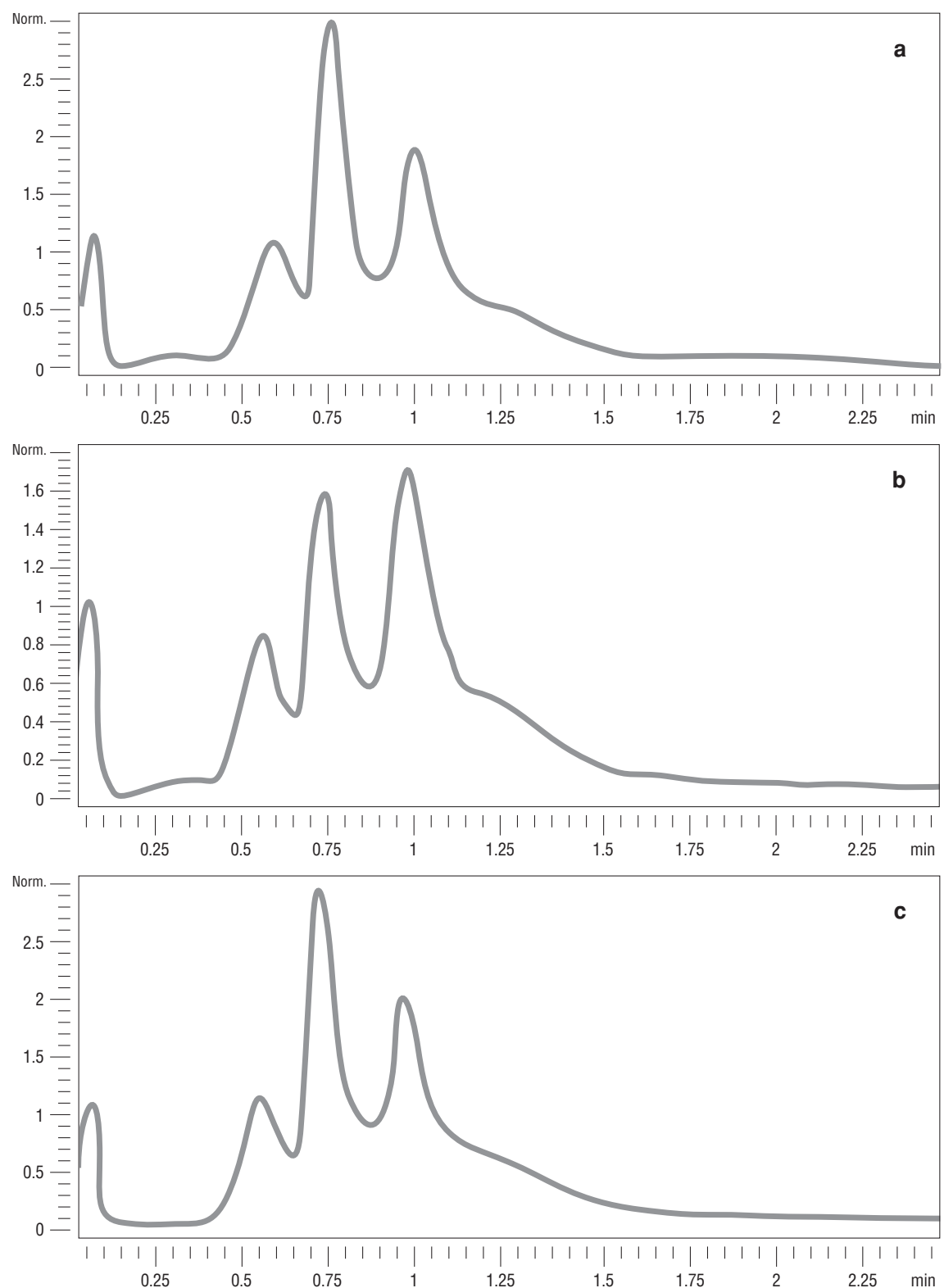

Figure 4. Chromatogram of placebo formulations a: D-2 b: E-1 c: F-4

\section{Precision}

Results of intermediate precision and repeatability tests on different concentrations are given in Table 7. RSD values for both intermediate precision and repeatability were $<2 \%$. Therefore, the method developed for FLB was found to be precise according to the suggestions in ICH Q2(R1) guidelines and also in literature. ${ }^{23}$ 
Table 7. Precision results for $15 \mu \mathrm{g} \cdot \mathrm{mL}^{-1} 30 \mu \mathrm{g} \cdot \mathrm{mL}^{-1} 45 \mu \mathrm{g} \cdot \mathrm{mL}^{-1}$ of FLB

\begin{tabular}{|c|c|c|c|c|c|}
\hline \multicolumn{3}{|c|}{ Area/Rt } & \multicolumn{3}{|c|}{ Concentration $\left(15 \mu \mathrm{g} \cdot \mathrm{mL}^{-1}\right)$} \\
\hline 1st day & 2nd day & 3rd day & 1st day & 2nd day & 3rd day \\
\hline 218.4481 & 206.6694 & 218.7202 & 15.6344 & 14.8642 & 15.6522 \\
\hline 220.0384 & 205.5260 & 216.8623 & 15.7384 & 14.7894 & 15.5307 \\
\hline 213.0078 & 203.1071 & 213.5887 & 15.2787 & 14.6312 & 15.3166 \\
\hline Mean & 15.5505 & 14.7616 & 15.4999 & & \\
\hline \multicolumn{3}{|c|}{ Standard deviation (SD) } & 0.2411 & 0.1189 & 0.1699 \\
\hline \multicolumn{3}{|c|}{ Coefficient of variation (RSD) } & 1.5504 & 0.8057 & 1.0961 \\
\hline \multicolumn{3}{|c|}{$95 \%$ confidence interval } & 0.5989 & 0.2995 & 0.4220 \\
\hline \multicolumn{3}{|c|}{ Area/Rt } & \multicolumn{3}{|c|}{ Concentration $(30 \mu \mathrm{g} \cdot \mathrm{mL}-1)$} \\
\hline 1st day & 2nd day & 3rd day & 1st day & 2nd day & 3rd day \\
\hline 452.4530 & 440.2308 & 460.0505 & 30.9369 & 30.1376 & 31.4337 \\
\hline 435.4347 & 455.5667 & 445.2264 & 29.8240 & 31.1405 & 30.4643 \\
\hline 444.1183 & 451.2570 & 445.6063 & 30.3918 & 30.8587 & 30.4891 \\
\hline Mean & 30.3842 & 30.7122 & 30.7957 & & \\
\hline \multicolumn{3}{|c|}{ Standard deviation (SD) } & 0.5565 & 0.5172 & 0.5527 \\
\hline \multicolumn{3}{|c|}{ Coefficient of variation (RSD) } & 1.8315 & 1.6841 & 1.7946 \\
\hline \multicolumn{3}{|c|}{$95 \%$ confidence interval } & 1.3824 & 1.2848 & 1.3729 \\
\hline \multicolumn{3}{|c|}{ Area/Rt } & \multicolumn{3}{|c|}{ Concentration $\left(45 \mu \mathrm{g} \cdot \mathrm{mL}^{-1}\right)$} \\
\hline 1st day & 2nd day & 3rd day & 1st day & 2nd day & 3rd day \\
\hline 452.4530 & 440.2308 & 460.0505 & 30.9369 & 30.1376 & 31.4337 \\
\hline 435.4347 & 455.5667 & 445.2264 & 29.8240 & 31.1405 & 30.4643 \\
\hline 444.1183 & 451.2570 & 445.6063 & 30.3918 & 30.8587 & 30.4891 \\
\hline Mean & 30.3842 & 30.7122 & 30.7957 & & \\
\hline \multicolumn{3}{|c|}{ Standard deviation (SD) } & 0.5565 & 0.5172 & 0.5527 \\
\hline \multicolumn{3}{|c|}{ Coefficient of variation (RSD) } & 1.8315 & 1.6841 & 1.7946 \\
\hline \multicolumn{3}{|c|}{$95 \%$ confidence interval } & 1.3824 & 1.2848 & 1.3729 \\
\hline
\end{tabular}

\section{Limit of detection and limit of quantitation (sensitivity)}

Analytical method development and validation procedures are very important for the discovery and development of drugs. LOD and LOQ parameters are interrelated, but have different definitions and should not be confused. There are a few definitions used to describe LOD and LOQ. In general, an LOD is detected as the lowest concentration in a sample under the conditions specified in the test, but is not considered to be quantifiable. LOQ is the lowest concentration of an analyte in a test and can be determined with acceptable precision and accuracy under the specified test conditions. There are several common methods for estimating 
the detection and quantification limit, which can be listed as follows; signal-tonoise, blank determination, linear regression, limit of blank and precision-based approaches. ${ }^{24,25}$ In this study, LOD and LOQ were calculated by linear regression and found as $0.0607 \mu \mathrm{g} \cdot \mathrm{mL}-1$ and $0.1840 \mu \mathrm{g} . \mathrm{mL}^{-1}$, respectively. The linear regression method used in this study can be applied in every situation and the analysis method is most suitable if it does not contain noise in the background. The calibration curve uses a series of low values close to zero and results in a more relevant evaluation with a more homogeneous distribution. ${ }^{25}$

\section{Accuracy}

As shown in Table 8 perfect recoveries of FLB at various concentrations were obtained between $100.3863-101.0911 \%$ and also RSD values for all concentration were $<2 \% .25,26$ Table 8 indicates good accuracy of the UPLC method developed in this study.

Table 8. Accuracy results for $20 \mu \mathrm{g} \cdot \mathrm{mL}-130 \mu \mathrm{g} \cdot \mathrm{mL}-140 \mu \mathrm{g} \cdot \mathrm{mL}-1$ of FLB

\begin{tabular}{|c|c|c|c|c|c|}
\hline \multicolumn{3}{|c|}{ Area/Rt } & \multicolumn{3}{|c|}{ Concentration } \\
\hline $\mathbf{2 0} \boldsymbol{\mu g} \cdot \mathrm{mL}^{-1}$ & $\mathbf{3 0} \boldsymbol{\mu g} \cdot \mathrm{mL}^{-1}$ & $\mathbf{4 0} \boldsymbol{\mu g} \cdot \mathrm{mL}^{-1}$ & $\mathbf{2 0} \boldsymbol{\mu g} \cdot \mathrm{mL}^{-1}$ & $\mathbf{3 0} \boldsymbol{\mu g} \cdot \mathrm{mL}^{-1}$ & $\mathbf{4 0} \boldsymbol{\mu g} \cdot \mathrm{mL}^{-1}$ \\
\hline 287,4006 & 438,4561 & 598,9059 & 20,1435 & 30,0216 & 40,5140 \\
\hline 285,9462 & 441,4241 & 595,5505 & 20,0484 & 30,2156 & 40,2945 \\
\hline 286,4823 & 439,8155 & 598,7052 & 20,0834 & 30,1105 & 40,5008 \\
\hline \multirow{3}{*}{} & \multicolumn{3}{|c|}{ Recovery \% } \\
\cline { 2 - 5 } & $\mathbf{2 0} \boldsymbol{\mu g} \cdot \mathrm{mL}^{-1}$ & $\mathbf{3 0} \boldsymbol{\mu g} \cdot \mathrm{mL}^{-1}$ & $\mathbf{4 0} \boldsymbol{\mu g} \cdot \mathrm{mL}^{-1}$ \\
\cline { 2 - 5 } & 100,7174 & 100,0718 & 101,2849 \\
\cline { 2 - 5 } & 100,2418 & 100,7188 & 100,7363 \\
\cline { 2 - 5 } & 100,4171 & 100,3682 & 101,2521 \\
\hline Recovery \% (mean) & 100.4588 & 100.3863 & 101.0911 \\
\hline Difference \% & 0.4588 & 0.3863 & 1.0911 \\
\hline Standard deviation & 0.2405 & 0.3239 & 0.3077 \\
\hline Coefficient of variation (RSD) & 0.2394 & 0.3226 & 0.3044 \\
\hline Standart Error & 0.0982 & 0.1322 & 0.1256 \\
\hline \multicolumn{3}{|c|}{ 95 confidence interval } & 0.5974 & 0.8045 & 0.7643 \\
\hline
\end{tabular}

\section{Robustness}

Results were obtained for area response and retention time, \% RSD was calculated and examined for robustness. \% RSD for retention time for six different condutions were between 0.20 and $0.76 \%$ (Table 9), which is is well inside the proposed acceptance basis of $\leq 5 \%$. Percent RSD for area response was from 0.09 to $0.73 \%$, which also passed the proposed acceptance basis of $\leq 2 \% .{ }^{26,27,28}$ Therefore, it can be concluded that the method is consistent in front of the wavelength, temperature, flow and $\mathrm{pH}$ of mobile phase. 
Table 9. \%RSD for robustness study $(n=6)$

\begin{tabular}{|c|c|c|}
\hline No & \%RSD, Retention Time & \%RSD, Peak Area \\
\hline 1 & 0.20 & 0.09 \\
\hline 2 & 0.63 & 0.73 \\
\hline 3 & 0.76 & 0.73 \\
\hline 4 & 0.63 & 0.68 \\
\hline 5 & 0.72 & 0.24 \\
\hline 6 & 0.28 & 0.11 \\
\hline
\end{tabular}

\section{Gel characterization studies}

\section{Physical appearence}

All gel formulations showed good homogeneity in the absence of pellets. Their color was determined to be transparent both in the placebo and in the active ingredient formulations. ${ }^{29,30}$

\section{pH}

$\mathrm{pH}$ results of prepared gel formulations were shown in Table 10. The $\mathrm{pH}$ of all gel formulations were found near to the skin $\mathrm{pH}$, that showed the gels were suitable for topical delivery. ${ }^{31}$

Table 10. Result of pH and drug content

\begin{tabular}{|c|c|c|}
\hline Code & pH & Drug content (\%) \\
\hline D-7 & $5.79 \pm 0.26$ & $98.14 \pm 0.06$ \\
\hline E-6 & $5.82 \pm 0.21$ & $98.21 \pm 0.04$ \\
\hline F-9 & $5.71 \pm 0.39$ & $99.02 \pm 0.02$ \\
\hline
\end{tabular}

*all result gives with standart error

\section{Rheological Characterization}

Rheological measurements were performed for carbopol, MC and HPMC gels. The results of these measurements are presented in Figure 5. Flow index provides an idea about the flow properties of the formulation from the container.

All gels are clearly shear thinning fluids and have the tendency to become nonNewtonian at low shear rates. The pseudoplasticity is because of the gelling structure, which lead to decrease in viscosity with increase in shear rate. ${ }^{32,33}$ Because of the pseudoplastic flow, the gel system will require application of some force to take. The sheer stress/ shear rate datas for Casson Model were compatible with the literature. ${ }^{32}$ Flow curves obtained at room temperatures indicate gels show 
significant pseudoplastic behavior with a Casson Model ranging from 10 to $20 \mathrm{~s}^{-1}$ (Figure 5). Non-Newtonian flow properties in gel formulations can be found to the increased solvent-solvent and polymer-solvent attractions and higher viscosity of cosolvent. ${ }^{33.35}$
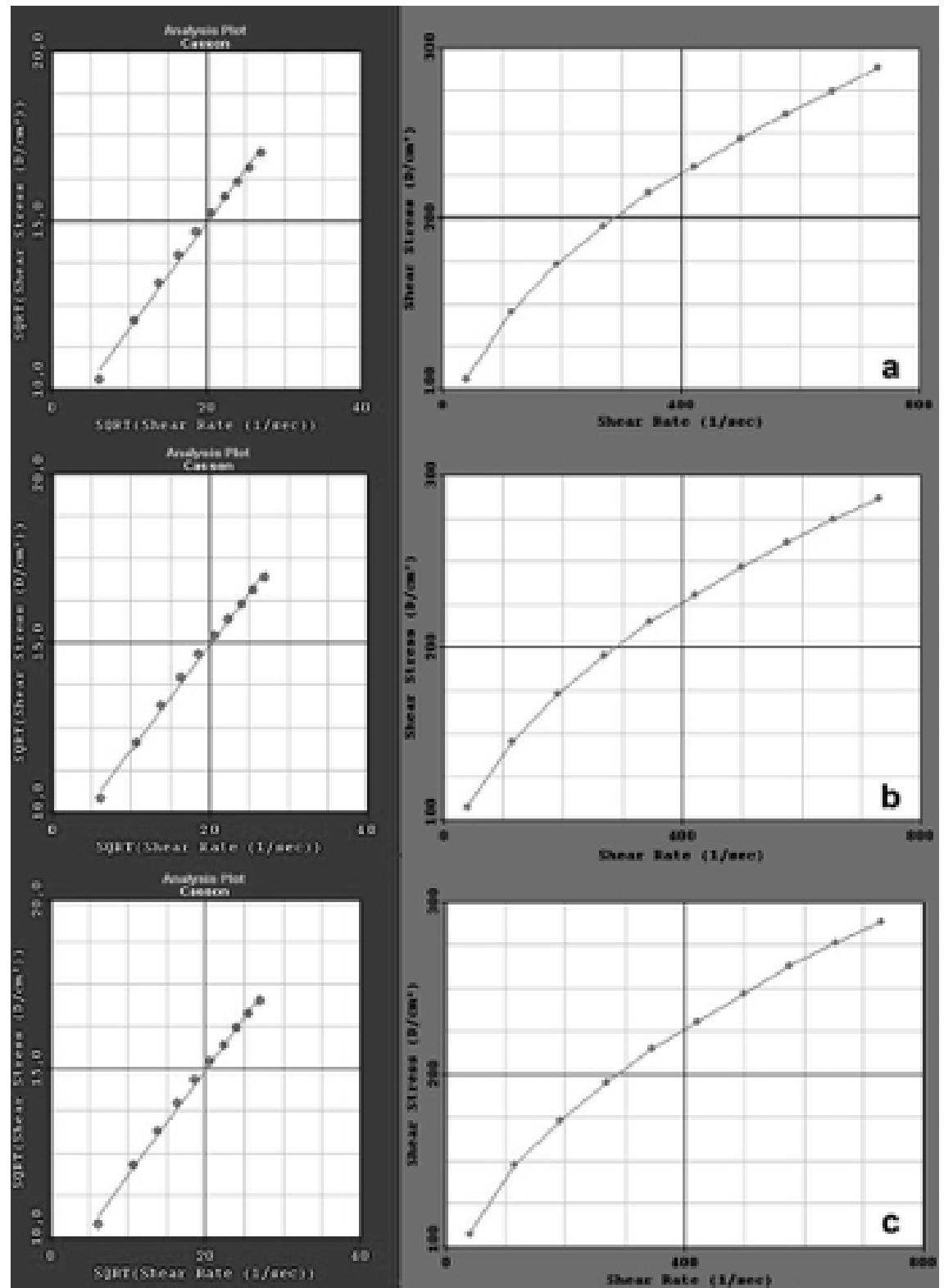

Figure 5. Rheological measurements results a: D-7 b: E-6 c: F-9 


\section{Drug content}

In the prepared gel formulations, the drug content was found to be in the range of 98.14-99.02 \% indicating the uniformity of the high drug content. ${ }^{35,36}$ The drug content results of the gel formulations are shown in Table 10.

\section{Dissolution study}

In vitro dissolution profile of FLB gels containing different gelling agent are shown in Figure 6. The initial concentration of FLB in all gel formulations was kept constant at 0.2 grams. It was determined that the release rate of pure FLB reached 100\% within 2 hours. At the end of the 6th hour, the FLB release from gels prepared with MC (D-7) and HPMC (E-6) reached $99.7 \%$ and $99.5 \%$ respectively. The release rate of the gel prepared with C-940 (F-9) was 87.60\%. Viscosity is negatively related to the formulation release of the active ingredients and their penetration through diffusion barriers. The reduction in release can be attributed to the excess viscosity of the F-7 coded formulation over the other two formulations.35 In the light of these results, it was observed that the polymer type and viscosity was the most affected factor in releasing the drug. ${ }^{36}$ At the same time the results suggest that formulations prepared according to pure FLB have prolonged release.

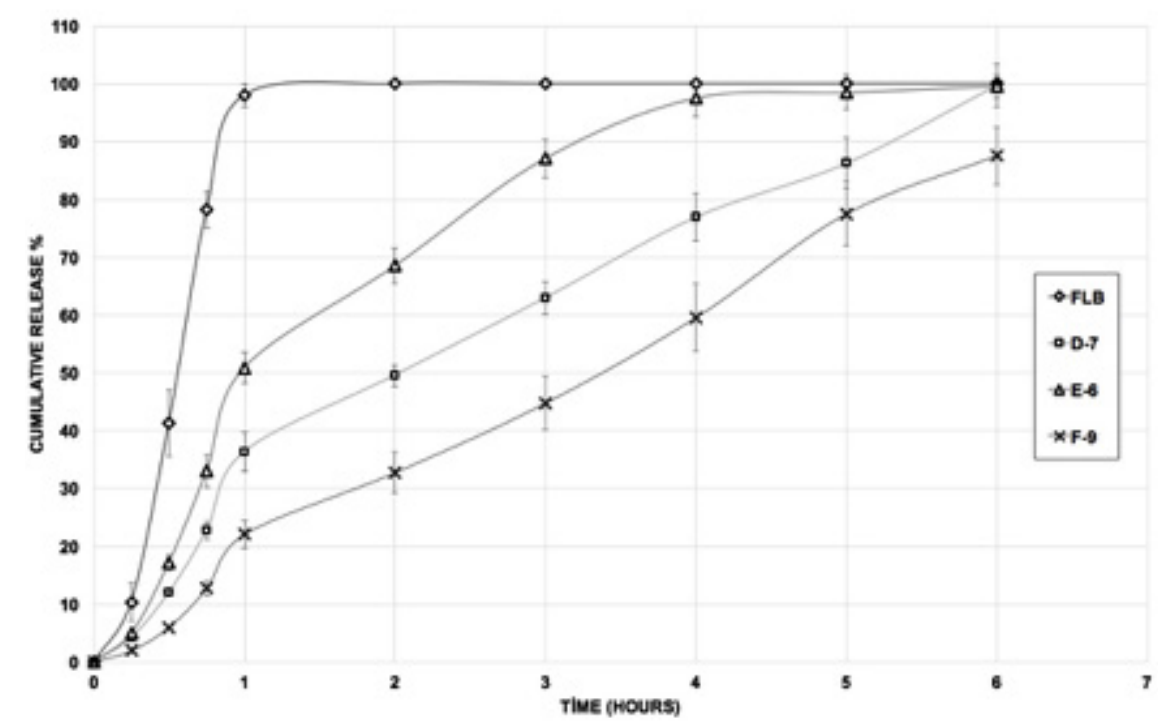

Figure 6. In vitro release of pure FLB and FLB loaded gels 


\section{Release kinetics}

Dissolution testing is a crucial analysis for both drug research development and quality control because it determines the rate and extent of drug release from oral pharmaceutical products. Dissolution data analysis is determined by statistically or mathematically comparing the dissolution profiles to quantify or characterize drug release from a pharmaceutical formulation. ${ }^{21}$ Almost all of the commercial statistical software programs used on the pharmaceutical field are designed for evaluating pharmacokinetic parameters (in vivo study), not for statistical evaluation of dissolution profiles (in vitro dissolution study). To reduce computation time and eliminate computational errors, researchers designed the DDsolver program, an excel add-in program that allows modeling of dissolution data using a different dissolution model. The program provides an efficient data analysis report to summarize the analysis of the dissolution data. ${ }^{21,37}$ In this study, different kinetic models were applied on release data for categorizing the kinetics of drug release with DDSolver computer program. This program was used to shorten the calculation time, to eliminate calculation errors and to determine the correct release profile. When all optimum gel formulations were analyzed for cumulative solubility in time versus time, all formulations appeared to be continuously released for 6 hours. After calculation, the data is transferred to the DDSolver program to determine five important and the most popular criteria. These criteria are based on the coefficient of determination (Rsqr, $\mathrm{R}^{2}$, or COD), the adjusted coefficient of determination (Rsqr_adj or $\mathrm{R}_{\text {adjusted }}$ ), the Akaike Information Criterion (AIC), the Model Selection Criterion (MSC) and $\mathrm{n}$ for only korsmeyer peppas models. The highest $\mathrm{R}^{2}, \mathrm{R}^{2}$ adjusted and MSC values and the lowest AIC values are used for the evaluation. ${ }^{21,38}$ Zero-order kinetic, First-order kinetic, Higuchi, Korsmeyer-Peppas, Korsmeyer-Peppas with $\mathrm{T}_{\text {lag }}$, Korsmeyer-Peppas with $\mathrm{F}_{\mathrm{o}}$ and Weibull models were selected for evaluation in DDSolver program. As a result of applying in vitro release study data obtained to different kinetic models using DDSolver program; $\mathrm{R}^{2}, \mathrm{R}_{\text {adjusted }}^{2} \mathrm{MSC}$, AIC found are shown in Table 11. 
Table 11. Kinetic modeling of gel formulation by DDSolver program

\begin{tabular}{|c|c|c|c|c|c|c|}
\hline \multirow[b]{2}{*}{ Code } & \multirow[b]{2}{*}{ Model and Equation } & \multicolumn{5}{|c|}{ Evaluation Criter } \\
\hline & & R2 & \begin{tabular}{|c|}
$\mathbf{R 2}$ \\
adjusted
\end{tabular} & AIC & MSC & $\mathbf{n}$ \\
\hline $\mathrm{D}-7$ & \multirow{3}{*}{$\begin{array}{l}\text { Zero-order model } \\
\qquad F=k_{0}{ }^{*} t\end{array}$} & 0.914 & 0.914 & 62.067 & 2.226 & - \\
\hline $\mathrm{E}-6$ & & 0.686 & 0.686 & 75.256 & 0.935 & - \\
\hline F-9 & & 0.990 & 0.990 & 41.027 & 4.404 & - \\
\hline $\mathrm{D}-7$ & \multirow{3}{*}{$\begin{array}{l}\text { First-order model }{ }^{*} \\
F=100^{*}\left[1-\operatorname{Exp}\left(-k_{1}{ }^{*} t\right)\right]\end{array}$} & 0.812 & 0.812 & 69.051 & 1.450 & - \\
\hline $\mathrm{E}-6$ & & 0.974 & 0.974 & 52.874 & 3.422 & - \\
\hline F-9 & & 0.948 & 0.948 & 56.083 & 2.728 & - \\
\hline $\mathrm{D}-7$ & \multirow{3}{*}{$\begin{array}{l}\text { Higuchi model } \\
\qquad \mathrm{F}=\mathrm{k}_{\mathrm{H}}{ }^{*} \mathrm{t}^{0.5}\end{array}$} & 0.934 & 0.934 & 59.633 & 2.496 & - \\
\hline$E-6$ & & 0.920 & 0.920 & 62.917 & 2.306 & - \\
\hline F-9 & & 0.859 & 0.859 & 64.982 & 1.739 & - \\
\hline $\mathrm{D}-7$ & \multirow{3}{*}{$\begin{array}{c}\text { Korsmeyer-Peppas }{ }^{*} \\
\quad F=k_{K P}{ }^{*} t^{n}\end{array}$} & 0.910 & 0.897 & 64.469 & 1.959 & 0.915 \\
\hline $\mathrm{E}-6$ & & 0.882 & 0.865 & 68.451 & 1.691 & 0.431 \\
\hline$F-9$ & & 0.970 & 0.966 & 52.984 & 3.072 & 0.956 \\
\hline $\mathrm{D}-7$ & \multirow{3}{*}{$\begin{array}{c}\text { Korsmeyer-Peppas with Tlag } \\
\text { model } \\
\mathrm{F}^{*}=\mathrm{k}_{\mathrm{KP}}{ }^{*}\left(\mathrm{t}-\mathrm{T}_{\text {lag }}\right)^{\mathrm{n}}\end{array}$} & 0.939 & 0.919 & 62.893 & 2.134 & 0.820 \\
\hline $\mathrm{E}-6$ & & 0.864 & 0.819 & 71.692 & 1.331 & 0.389 \\
\hline F-9 & & 0.976 & 0.968 & 53.203 & 3.048 & 1.003 \\
\hline D-7 & \multirow{3}{*}{$\begin{array}{c}\text { Korsmeyer-Peppas with F0 } \\
\text { model }{ }^{*} \\
\mathrm{~F}_{\mathrm{F}} \mathrm{F}_{0}+\mathrm{k}_{\mathrm{KP}}{ }^{*} \mathrm{t}^{\mathrm{n}}\end{array}$} & 0.845 & 0.794 & 71.297 & 1.200 & 1.027 \\
\hline $\mathrm{E}-6$ & & 0.752 & 0.670 & 77.107 & 0.729 & 0.485 \\
\hline F-9 & & 0.904 & 0.872 & 65.558 & 1.675 & 1.236 \\
\hline D-7 & \multirow{3}{*}{$\begin{array}{c}\text { Weibull model }{ }^{*} \\
F=100^{*}\left\{1-\operatorname{Exp}\left[-\left((t-T i)^{\beta}\right) / \alpha\right]\right\}\end{array}$} & 0.987 & 0.965 & 58.015 & 2.676 & - \\
\hline $\mathrm{E}-6$ & & 0.994 & 0.987 & 50.482 & 3.688 & - \\
\hline F-9 & & 0.990 & 0.979 & 51.921 & 3.190 & - \\
\hline
\end{tabular}

* In all models, $F$ is the fraction (\%) of drug released in time $t, k_{0}$ : zero-order release constant, $k_{1}$ :bfirst-order release constant, $k_{\mathrm{H}}$ : Higuchi release constant, $k_{\mathrm{KP}}$ : release constant incorporating structural and geometric characteristics of the drug-dosage form, $n$ : is the diffusional exponent indicating the drug-release mechanism, $F_{0}$ is the initial fraction of the drug in the solution resulting from a burst release, $\alpha$ : is the scale parameter which defines the time scale of the process; $\beta$ : is the shape parameter which characterizes the curve as either exponential ( $\beta=1$; case 1), sigmoid, S-shaped, with upward curvature followed by a turning point $(\beta>1$; case 2$)$, or parabolic, with a higher initial slope and after that consistent with the exponential $(\beta<1$; case 3$)$, Ti: is the location parameter which represents the lag time before the onset of the dissolution or release process and in most cases will be near zero, $T_{\text {lag }}$ : is the lag time prior to drug release.

For gel formulations prepared with cellulose derivatives; the release of FLB from D-7 and E-6 coded formulations was consistent with the Weibull model according to the criterion. The results in this study can be verified on the grounds of previous cellulose derivates studies which demonstrates that researchers mostly emerged 
as the most appropriate model for the Weibull model. ${ }^{39,40,41}$ From the gel formulation prepared with C-940 (F-9), the release of FLB had zero-order kinetics according to the criterion. This rate of release is preferred because the drug is given in a constant rate for a long time. For the gel formulation prepared with C-940 (F-9), the $\mathrm{n}$ value of the Korsymear-Peppas, Korsymear-Peppas with Tlag model and Korsymear-Peppas with Fo model is closer to 1. This information indicates the zero order kinetics. ${ }^{14}$ The release kinetic profiles corresponding to all models are automatically extracted from the program and presented in Figure 7.
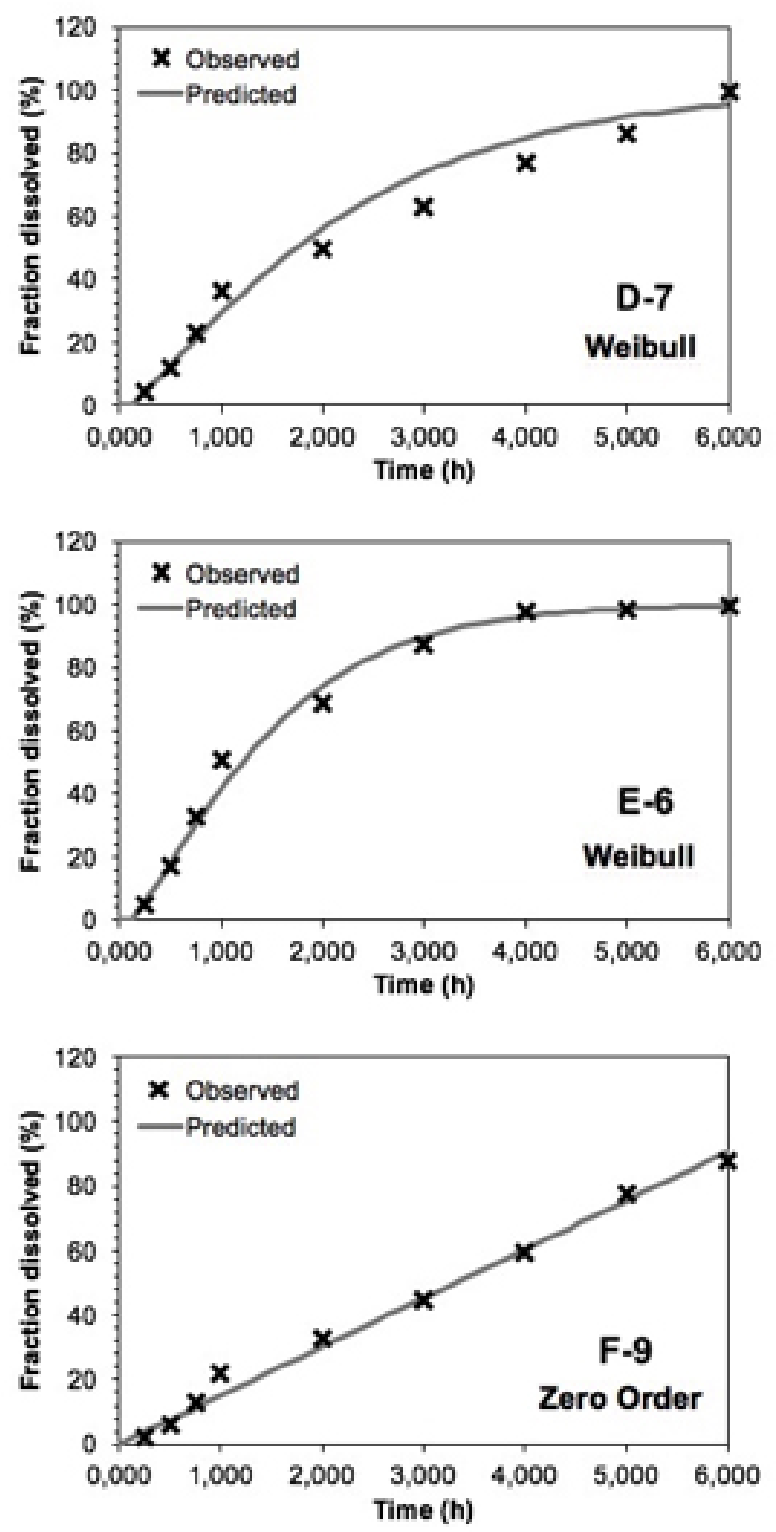

Figure 7. Automated release kinetic profiles of gel formulations from DDSolver software for more suitable model 


\section{CONCLUSION}

According to the in vitro studies results, a useful methodology for the detection of FLB in topical formulations has been established, which will provide a future basis for the development of a topical dosage form of the drug with a desired release profile. The general rank order of FLB release from the formulations was determined as MC > HPMC > C-940. Gel formulations of HPMC and MC have been observed to give higher values of drug release, which is due to the higher solubility of the drug. Pseudoplastic flows with thixotropy were obtained for all FLB-gels. Thus, these developed systems could be a promising vehicle for topical delivery of FLB. Additionally, in this study also a new, economic, easy and sensitive ultra performance liquid chromatography method was developed for the determination of FLB. The method developed for FLB was decided to be precise due to RSD values of $<2 \%$ for repeatability and intermediate precision. Recovery of the method was satisfactory owing to $<2 \%$ RSD value. The drug content was found to be in the range of 98.14-99.02\% indicating the uniformity of the high drug content. In the release kinetic tests with DDSolver, the release of gels prepared with methylcellulose and hydroxypropyl methylcellulose showed conformity with the weibull model, whereas the gel formulation prepared with Carbopol ${ }^{\circledR} 940$ showed a zero-order kinetics. In the case of different variants of similar polymer formulations, it was found that having a higher viscosity with a hyrophylic polymer released a higher amount of drug compared with the carbopol formulations. Further studies will be focused on the in vivo animal studies and tissue distribution in order to get a proper insight into the potential of polymeric based gel formulations in topical delivery.

\section{CONFLICT OF INTEREST}

The authors declare no conflict of interest, financial or otherwise.

\section{ACKNOWLEDGEMENTS}

The authors would like to thank Sanovel (İstanbul, Turkey) for providing a gift sample of Flurbiprofen.

\section{REFERENCES}

1. Ong, C.K.S.; Lirk, P.; Tan C.H.; Seymour, R.A. An evidence-based update on nonsteroidal anti-inflammatory drugs. $C M \& R, \mathbf{2 0 0} 7,5(1), 19-34$.

2. Ofman, J.J.; MacLean, C.H.; Straus, W.L.; Morton, S.C.; Berger, M.L.; Roth, E.A.; Shekelle, P. A metaanalysis of severe upper gastrointestinal complications of nonsteroidal antiinflammatory drugs. J. Rheumatol. 2002, 29, 804-812.

3. Maroof, K.; Zafar, F.; Ali H.; Naveed, S. Flurbiprofen: a potent pain reliever. $J$ Bioequiv. Availab. 2015, 7(1), 56-58. 
4. Askholt, J.; Nielsen-Kudsk, F. Rapid HPLC-determination of ibuprofen and flurbiprofen in plasma for therapeutic drug control and pharmacokinetic applications. Acta. Pharmacol. Toxicol. (Copenh). 1986, 59(5),382-386.

5. Park, K.M.; Gao, Z.G.; Kim, C.K. Assay of flurbiprofen in rat plasma using hplc with fluorescence detection, J. Liq. Chromatogr. Relat. Technol. 1997, 20(12),1849-1855.

6. Akhlaq, M.; Khan, G.M.; Wahab A.; et al. A simple high-performance liquid chromatographic practical approach for determination of flurbiprofen, J. Adv. Pharm. Technol. Res. 2011, 2(3),151-155.

7. Khan, I.U.; Razzaq, S.N.; Mariam, I.; Ashfaq, M.; Razzaq, S.S. Stability-indicating rp-hplc method for simultaneous determination of gatifloxacin and flurbiprofen in binary combination, Quim. Nova. 2014, 37(2), 349-354.

8. Siddiraju, S.; Kavitha, R.; Sudhakar, M. Reverse phase high performance liquid chromatography method development and validation for the simultaneous estimation of gatifloxacin and flurbiprofen in pharmaceutical dosage form, Asian. J. Pharm. Clin. Res. 2015, 8(1), 242-246.

9. Novakova, L.; Matysova, L.; Solich, P. Advantages of application of UPLC in pharmaceutical analysis, Talanta. 2006, 68, 908-918.

10. Kaur, L.P.; Guleri, T.K. Topical gel: a recent approach for novel drug delivery, Asian. J. Biomed. Pharm. Scie. 2013, 3(17), 1-5.

11. Hamas, M.A.A.; Ates, S.; Durmaz, E. Evaluation of the possilities for cellulose derivates in food products. Kastamonu. Univ. J. Fores. Fac. 2016, 16(2), 383-400.

12. Joshi, S.C.; Lam, Y.C.; Tan, B.K.; Liu, S.Q. Modeling of thermal gelation and degelation of MC and HPMC hydrogels, ICBPE 2006 - Proceedings of the 2006 International Conference on Biomedical and Pharmaceutical Engineering.2006 conferencepaper.DOI:10.1109/ ICBPE.2006.348654

13. A-sasutjarit, R.; Sirivat, A.; Vayumhasuwan, P. Viscoelastic properties of carbopol 940 gels and piroxicam diffusion coefficients in gel bases, Pharm. Res. 2005, 22(12), 2134-2140.

14. Sareen, R.; Kumar, S.; Gupta, G.D. Meloxicam carbopol-based gels: characterization and evaluation, Curr. Drug. Deliv. 2011, 8(4), 407-415.

15. Shrivastava, A.; Gupta, V.B. HPLC: isocratic or gradient elution and assessment of linearity in analytical methods. J. Adv. Sci Res. 2012, 3(2), 12-20.

16. Q2(R1) ICH Harmonised Tripartite Guideline (2014). Validation of Analytical Procedures: Text And Methodology.

17. Ermer, J.; Arth, C.; De Raeve, P.; Dill, D.; Friedel, H.D.; Höwer-Fritzen, H.; Kleinschmidt, G.; Köller, G.; Köppel, H.; Kramer, M.; Maegerlein, M.; Schepers, U. Watzig, H. Precision from drug stability studies: investigation of reliable repeatability and intermediate precision of HPLC assay procedures, J. Pharm. Biomed. Anal. 2005, 38(4), 653-663.

18. Vial, J.; Jardy, A. Experimental comparison of the different approaches to estimate LOD and LOQ of an HPLC method. Anal. Chem. 1999, 71(14), 2672-2677.

19. Rouini, M.R.; Ardakani, Y.H.; Soltani, F.; Aboul-Enein, H.Y.; Foroumadi, A. Development and validation of a rapid HPLC method for simultaneous determination of tramadol, and its two main metabolites in human plasma, J. Chromatogr. B.20o6, 830 (2), 207-211.

20. Vikrant, K.; Sonali, N. Formulation and evaluation of topical flurbiprofen gel using different 
gelling agents, World. J. Pharm. Pharmace. Sci. 2014. 3(9), 654-633.

21. Zhang, Y.; Huo, M.; Zhou, J.; Zou, A.; Li, W.; Yao, C.; Xie, S. DDSolver: an add-in program for modeling and comparison of drug dissolution profiles, AAPS. J. 2010, 12, 263-71.

22. Shabir, G.A.; Validation of high-performance liquid chromatography methods for pharmaceutical analysis: understanding the differences and similarities between validation requirements of the us food and drug administration, the us pharmacopeia and the international conference on harmonization, J. Chromatogr. A. 2003, 987(1-2), 57-66.

23. Bhadra, S.; Das, S.C.; Roy, S.; Arefeen, S.; Rouf, A.S.S. Development and validation of rphplc method for quantitative estimation of vinpocetine in pure and pharmaceutical dosage forms, Chromatogr. Res. Int. 2011, Article ID 801656, doi:10.4061/2011/801656, 1-8.

24. Öztürk, A.A.; Yenilmez, E.; Yazan, Y. Development and validation of high performance liquid chromatography (HPLC) modified method for dexketoprofen trometamol. Eur. Int. J. Sci. Tech. 2017, 6(4), 33-41

25. Shrivastava, A.; Gupta, V.B. Methods for LOD and LOQ determination, Chron. Young. Sci. 2011, 2(1), 21-25.

26. Ye, C.; Liu, J.; Ren, F.; Okafo, N. Design of experiment and data analysis by JMP®(SAS institute) in analytical method validation, J. Pharm. Biomed. Anal. 2000, 23(2-3),581-589.

27. Pérez-Lozano, P.; Garcia-Montoya, E.; Orriols, A.; Miñarro, M.; Ticó, J.R.; Suñé-Negre, J.M. Development and validation of a new HPLC analytical method for the determination of alprazolam in tablets, J. Pharm. Biomed. Anal. 2004, 34(5), 979-987.

28. Sahoo, N.K.; Sahu, M.; Rao, P.S.; Rani, N.S.; Devi, J.I.; Ghosh, G. Validation of assay indicating method development of meloxicam in bulk and some of its tablet dosage forms by RPHPLC. SpringerPlus, 3(95) (2014) 1-6.

29. Sanna, V., Gavini, E., Cossu, M., Rassu, G., \& Giunchedi, P. Solid lipid nanoparticles (SLN) as carriers for the topical delivery of econazole nitrate: in- vitro characterization, ex-vivo and in-vivo studies. Journal of pharmacy and pharmacology. 2007, 59(8), 1057-1064.

30. Abrar, B.; Anis, S.; Tanu, B.; Singh, S. Formulation and in-vitro evaluation of NSAID's gel. International journal of current pharmaceutical research, 2012, 4(3).

31. Sanjay, D.; Mazumder, B.; Patel, J.R. Enhanced percutaneous permeability of acyclovir by dmso from topical gel formulation, Int. J. Pharm. Sci. Drug. Res. 2oo9, 1(1), 13-18.

32. Bhattacharya, S.; Bhat K.K. Steady shear rheology of rice-blackgram suspensions and suitability of rheological models, J. Food. Eng. 1997, 32(3), 241-250.

33. Islam, M.T.; Rodriguez-Hornedo, N.; Ciotti, S., Ackermann, C. Rheological characterization of topical carbomer gels neutralized to different pH. Pharm. Res. 2004, 21(7), 1192-1199.

34. Kelly, H.M.; Deasy, P.B.; Busquet, M.; Torrance, A.A. Bioadhesive, rheological, lubricant and other aspects of an oral gel formulation intended for the treatment of xerostomia. Int. J. Pharm. 2004, 278(2), 391-406.

35. Patel, J.; Patel, B.; Banwait, H.; Parmar, K.; Patel, M. Formulation and evaluation of topical aceclofenac gel using different gelling agent. Int. J. Drug Dev. Res. 2011, 3(1), 156-164.

36. Helal, D.A.; El-Rahman, D.A.; Abdel-Halim, S.; El-Nabarawi, M. Formulation and evaluation of fluconazole topical gel. Int. J. Pharm. Pharm. Sci. 2012, 4(5), 176-183. 
37. Zuo, J.; Gao, Y.; Bou-Chacra, N.; Löbenberg, R. Evaluation of the ddsolver software applications. BioMed. Res. 2014, Article ID 204925, 1-9.

38. Öztürk, A.A.; Yenilmez, E.; Arslan, R.; Şenel, B.; Yazan Y. Dexketoprofen TrometamolLoaded Kollidon ${ }^{\circledR}$ SR and Eudragit ${ }^{\circledR}$ RS 100 Polymeric Nanoparticles: Formulation and In Vitro-In Vivo Evaluation. Lat. Am. J. Pharm. 2017, 36(11), 2153-2165.

39. Koester, L.S.; Ortega, G.G.; Mayorga, P.; Bassani, V.L. Mathematical evaluation of in vitro release profiles of hydroxyl propyl methylcellulose matrix tablets containing carbamazepine associated to $\beta$-cyclodextrin, Eur. J. Pharm. Biopharm. 2004, 58, 177-179.

40. Lin, H.; Wang, P.; Hung, L.; Hsu, L. Evaluation of in vitro release profiles of developed membrane moderated transdermal delivery systems containing methylephedrine Hcl, ChiaNan. Annual. Bulletin. 2005, 31, 1-8.

41. Ghoshal, K.; Chandra, A. Mathematical modeling of drug release profiles for modified hydrophobic HPMC based gels. Pharmazie. 2012, 67(2), 147-155. 